Supplement of Atmos. Chem. Phys., 15, 5743-5760, 2015

http://www.atmos-chem-phys.net/15/5743/2015/

doi:10.5194/acp-15-5743-2015-supplement

(C) Author(s) 2015. CC Attribution 3.0 License.

(c) (i)

Atmospheric

Chemistry

and Physics

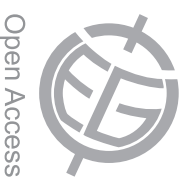

Supplement of

\title{
Using the OMI aerosol index and absorption aerosol optical depth to evaluate the NASA MERRA Aerosol Reanalysis
}

\section{Buchard et al.}

Correspondence to: V. Buchard (virginie.buchard@nasa.gov)

The copyright of individual parts of the supplement might differ from the CC-BY 3.0 licence. 


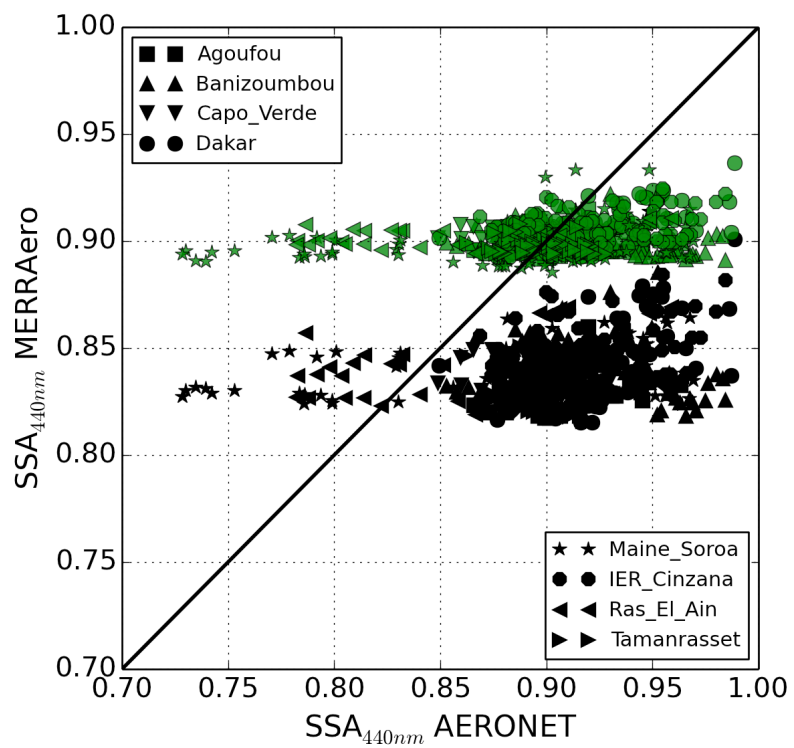

Fig. S1. Comparison of MERRAero SSA at $440 \mathrm{~nm}$ over the Saharan dust region using the OPAC dust optics in black and the observationbased dust optics in green with AERONET inversion products for the period June to October 2007. 

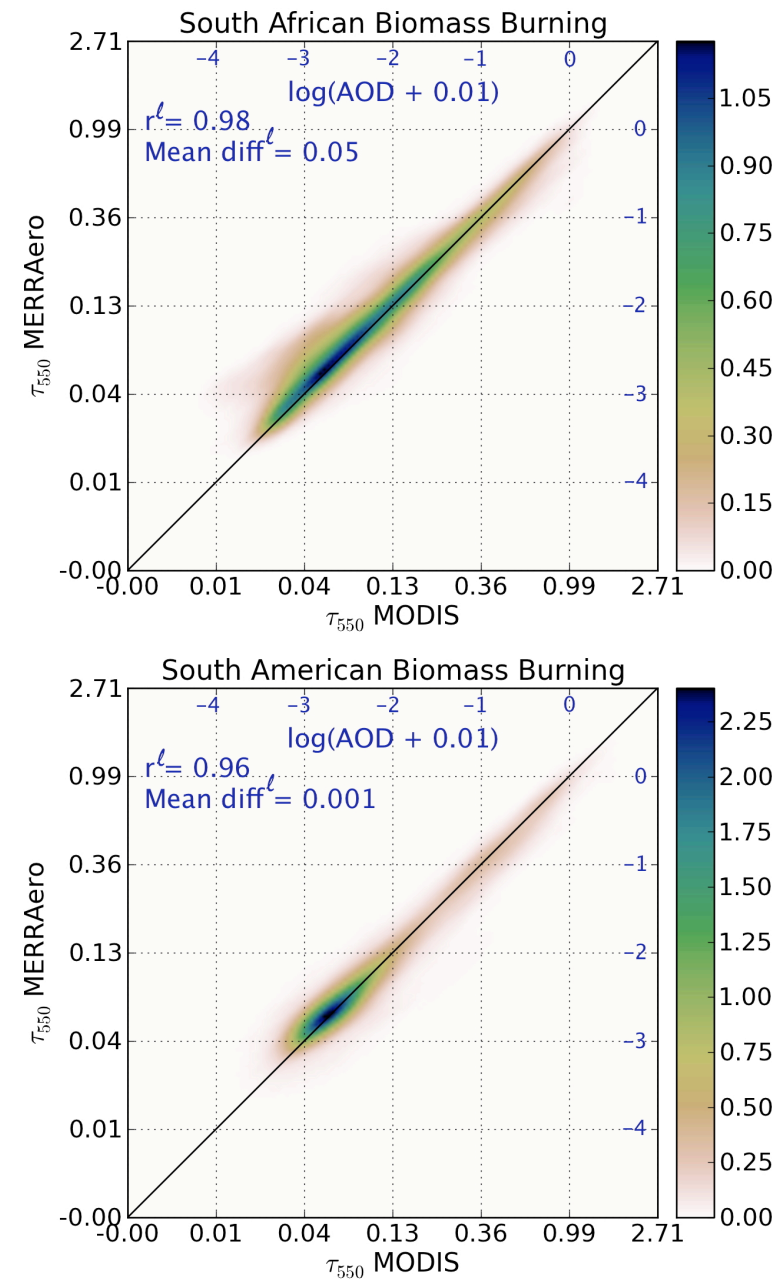

Fig. S2. Comparison of $550 \mathrm{~nm}$ MERRAero AOD to MODIS NNR retrievals over the south African (top) and South American (bottom) biomass burning regions for the period JJA 2007.
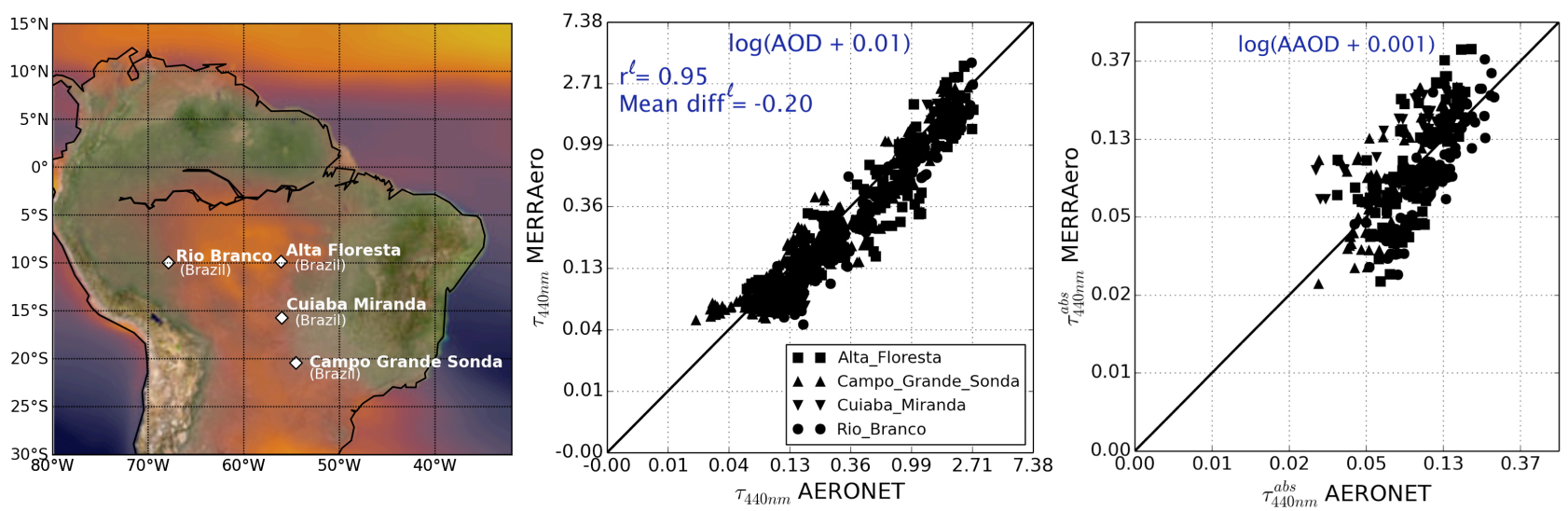

Fig. S3. Comparison of MERRAero and AERONET $440 \mathrm{~nm}$ AOD (middle) and AAOD (right) at 4 South American AERONET sites shown on the map (left) for the period June to October 2007. The one-to-one line is indicated by the black line. 

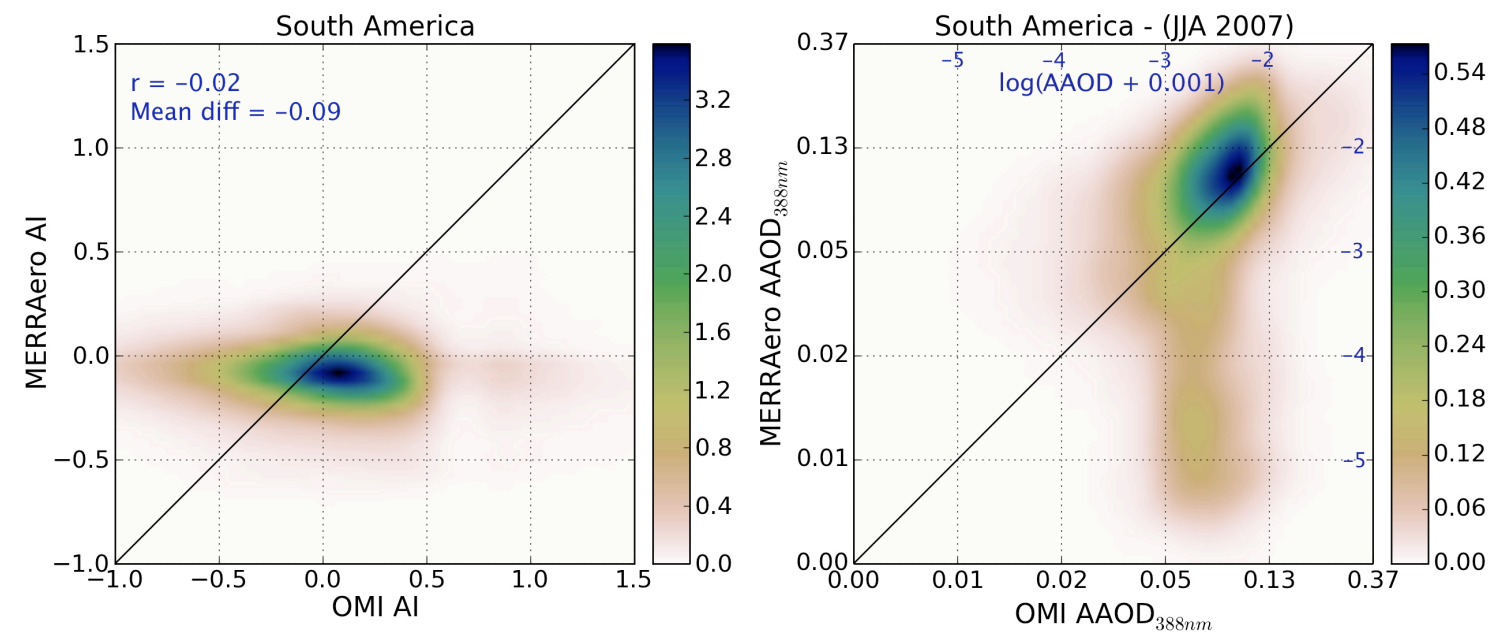

Fig. S4. Comparison of MERRAero simulated AI (left) and AAOD at 388nm (right) to OMI retrievals for the period JJA 2007 over the South American region.

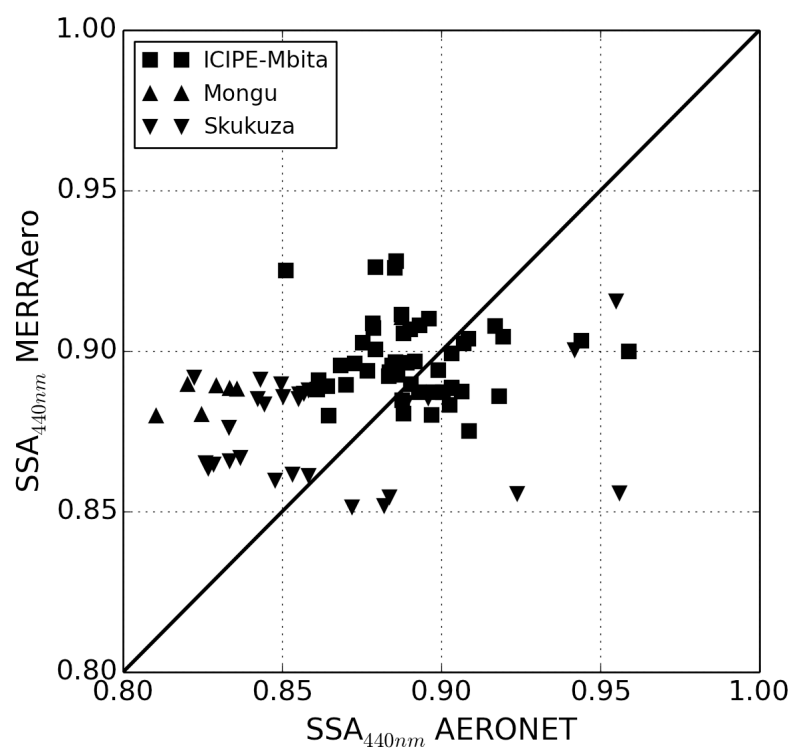

Fig. S5. Comparison of MERRAero SSA at $440 \mathrm{~nm}$ to AERONET inversion products over the south African region. 


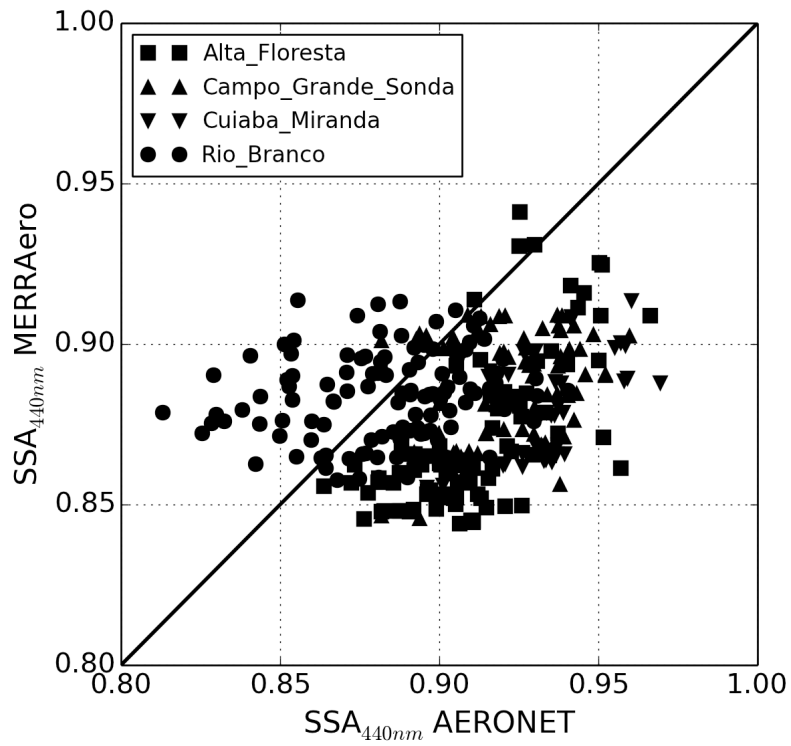

Fig. S6. Same as Fig. S5 but for the South American region

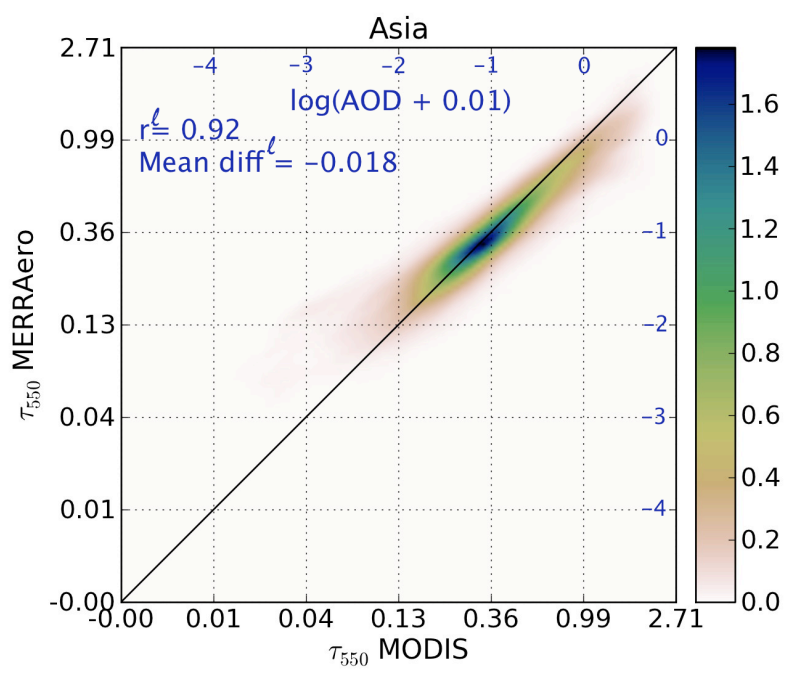

Fig. S7. Same as Fig. S2 but for the Asian region during AMJ 2007. 


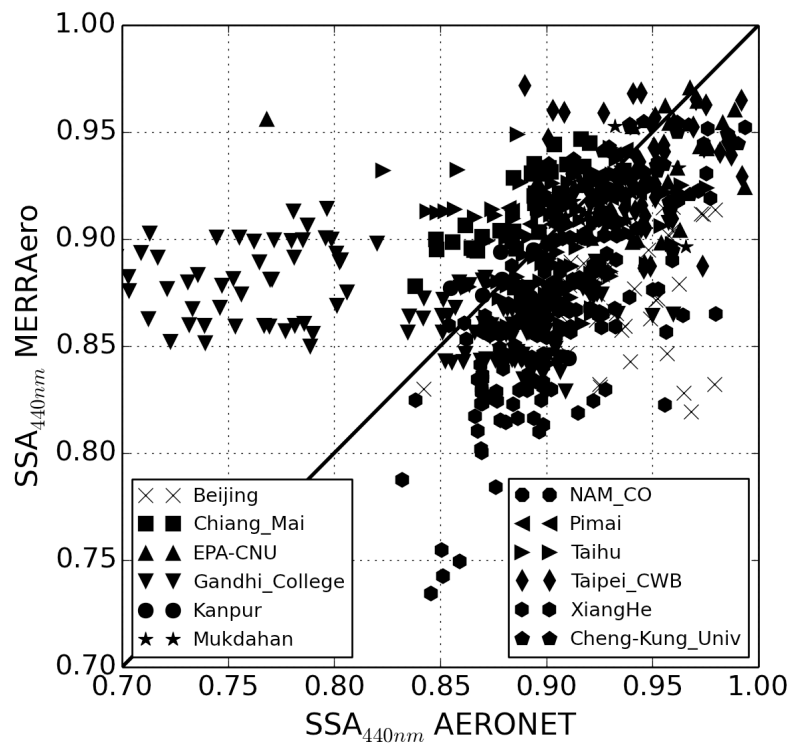

Fig. S8. Same as Fig. S5 but for the Asian region. 